\section{The exon 16-3t variant of the sulphonylurea receptor gene is not a risk factor for Type II diabetes mellitus in the Dutch Breda cohort}

Dear Sir,

't Hart et al. [1] analysed the association of two previously reported single nucleotide polymorphisms in the sulphonylurea receptor gene (SUR1) [2] with Type II (non-insulin-dependent) diabetes mellitus in the Netherlands [1]. They reported an association of the exon 16-3t variant with Type II diabetes mellitus by showing that the genotype frequencies between control subjects and Type II diabetic patients differed significantly $(p<0.05)$. This effect was even stronger when allele frequencies of the $t$-variant, rather than genotype frequencies, were compared between Type II diabetic patients (0.42) and control subjects $(0.48)(p=0.01)$.

We carried out an association study of the same exon 16-3t variant in our independent cohort of 566 Type II diabetic patients. All participating subjects were recruited by the Diabetes Service in Breda located in the western part of the province of North Brabant, the Netherlands. All participants were diagnosed according to the WHO criteria and the 150 control subjects were age and sex matched.

Genotyping assay of the SUR1 exon 16 polymorphism by PCR-RFLP was done as described by Hansen et al. [3]. This polymorphism consists of a $c \rightarrow t$ transition, three bp proximal to exon 16. The PCR primers used to amplify the polymorphic site were adjusted to create larger fragments. For this the following primers were used 5' GGGTAATGGTTGTTCAGACTCC 3 ' and 5' TGAGGAGGATGGTTAAAAGGAG $3^{\prime}$. Each possible genotype $(c / c, t / c$ and $t / t)$ was confirmed by sequence analysis of the different alleles and three patients, one from each genotype group, were used as control-standards in every assay. All 566 Type II diabetic patients and the 150 control subjects were genotyped twice in a blind assay.

The genotype and allele frequencies for the exon 16 polymorphism are presented in Table 1 , next to the results of 't Hart et al. [1]. We could not detect a significant association

Corresponding author: Dr. C. Wijmenga, Department of Medical Genetics, University Medical Centre Utrecht, PO Box 85090, 3508 AB Utrecht, The Netherlands between the $t$-allele of exon 16 and Type II diabetes mellitus in our cohort of patients $(p=0.31)$.

The frequency of the $t$-allele $(0.41)$ did not differ significantly between our patient and control group $(p=0.13)$ and was comparable to the $t$-allele frequency $(0.41)$ in the control group of "t Hart et al. (Table 1).

As a consequence, the calculated odds ratios of the $t$-allele in the two studies contradict each other. The presence of the $t$-allele found by ' $t$ Hart et al. [1] is associated with a 1.3 increase in risk of getting Type II diabetes mellitus, whereas our study shows an odds ratio of 0.82 , the difference between the two calculated odds ratios being significantly different $(p<0.01)$. There are several possible explanations for this difference: the use of different patients, different control subjects, different cohorts or stratification in general.

Firstly, the use of different patients. In our Breda cohort patients are mainly treated by diet or by sulphonylurea drugs and only $9.4 \%$ of our patients receive insulin as a therapy. 't Hart et al. used mainly newly diagnosed patients, and it is not known what kind of therapy they received. The $t$-allele is possibly associated with functional changes in the ATP-sensitive $\mathrm{K}^{+}$ channel in insulin-secreting pancreatic beta cells. One could hypothesise that if the $t$-allele alters the function of the ATPsensitive $\mathrm{K}^{+}$channel, the allele frequency could be higher in patients using insulin compared with patients using oral diabetic drugs (sulphonylurea derivatives). Hence, sulphonylurea derivatives possibly have little effect on the altered SURI gene product and patients with this variant might be put on insulin much sooner than patients without this variant. This may give rise to a higher presence of the $t$-allele in patients than in control subjects, if the $t$-allele of the SURl gene is associated with functional changes in the ATP-sensitive $\mathrm{K}^{+}$channel in insulin-secreting pancreatic beta cells.

Secondly, the use of different populations. 't Hart et al. sampled from two different cohorts, namely Rotterdam and Hoorn. The difference between our results and those of ' $t$ Hart et al. stems almost entirely from the Rotterdam patient group, with no contribution from the Hoorn cohort. Amongst the patients from the Rotterdam cohort there is an increased frequency of the $c / t$ genotypes $(0.57)$, compared with the frequency in patients from the Hoorn cohort and the Breda cohort ( 0.51 and 0.49 respectively).

Another explanation for this difference is the possibility of stratification or population admixture. Positive association can also arise as an artefact of population admixture. This 
Table 1. SUR 1 exon 16 variants in Dutch Type II diabetic patients

\begin{tabular}{|c|c|c|c|c|c|c|c|c|}
\hline \multirow[t]{2}{*}{ Genotype } & \multicolumn{2}{|c|}{ Breda Study } & \multicolumn{2}{|c|}{ 't Hart et al. [1] } & \multicolumn{2}{|c|}{ Rotterdam cohort $^{1}$} & \multicolumn{2}{|c|}{ Hoorn cohort $^{1}$} \\
\hline & $\begin{array}{l}\text { Control } \\
\text { subjects } \\
n=150\end{array}$ & $\begin{array}{l}\text { Patients } \\
n=566\end{array}$ & $\begin{array}{l}\text { Control } \\
\text { subjects } \\
n=336\end{array}$ & $\begin{array}{l}\text { Patients } \\
n=388\end{array}$ & $\begin{array}{l}\text { Control } \\
\text { subjects } \\
n=170\end{array}$ & $\begin{array}{l}\text { Patients } \\
n=196\end{array}$ & $\begin{array}{l}\text { Control } \\
\text { subjects } \\
n=166\end{array}$ & $\begin{array}{l}\text { Patients } \\
n=192\end{array}$ \\
\hline $\begin{array}{l}-3 c / c \\
-3 c / t \\
-3 t / t \\
\chi^{2} \mathrm{c} \text { vs } p^{2} \\
p \text {-value }\end{array}$ & $\begin{array}{l}0.29 \\
0.50 \\
0.21 \\
2.36 \\
0.31\end{array}$ & $\begin{array}{l}0.36 \\
0.47 \\
0.17\end{array}$ & $\begin{array}{l}0.33 \\
0.51 \\
0.16 \\
6.81 \\
0.03\end{array}$ & $\begin{array}{l}0.25 \\
0.54 \\
0.21\end{array}$ & $\begin{array}{l}0.31 \\
0.53 \\
0.16 \\
3.48 \\
0.18\end{array}$ & $\begin{array}{l}0.22 \\
0.57 \\
0.21\end{array}$ & $\begin{array}{l}0.35 \\
0.49 \\
0.16 \\
3.42 \\
0.18\end{array}$ & $\begin{array}{l}0.28 \\
0.51 \\
0.21\end{array}$ \\
\hline $\begin{array}{l}\text { Allele } \\
-3 c \\
-3 t \\
\chi^{2} \\
p \text {-value } \\
\text { OR } t \text {-allele } \\
95 \% \text { Cl-OR } t \text {-allele }\end{array}$ & $\begin{array}{l}0.54 \\
0.46 \\
2.30 \\
0.13 \\
0.82 \\
0.63-1.06\end{array}$ & $\begin{array}{l}0.59 \\
0.41\end{array}$ & $\begin{array}{l}0.59 \\
0.41 \\
6.24 \\
0.01 \\
1.30 \\
1.06-1.61\end{array}$ & $\begin{array}{l}0.52 \\
0.48\end{array}$ & $\begin{array}{l}0.57 \\
0.43 \\
2.90 \\
0.09 \\
1.29 \\
0.96-1.73\end{array}$ & $\begin{array}{l}0.51 \\
0.49\end{array}$ & $\begin{array}{l}0.60 \\
0.40 \\
3.36 \\
0.07 \\
1.32 \\
0.98-1.78\end{array}$ & $\begin{array}{l}0.53 \\
0.47\end{array}$ \\
\hline
\end{tabular}

${ }^{1}$ The different cohorts from Rotterdam and Hoorn used by 't Hart et al. [1]

${ }^{2}$ Chi-square of control subjects vs patients; OR, odds ratio

problem has afflicted many association studies done in inhomogeneous populations, ranging from the population of metropolitan Los Angeles to Native American tribes [4, 5]. Since Rotterdam is the city with the largest harbour in the world, it shows a mixed population due to continuous migration and immigration.

A combination of all the above mentioned points may explain the difference between the study by 't Hart and our study in the Dutch Breda cohort.

In conclusion, it appears that the SUR1 exon $16 t$-allele is not a risk factor for developing Type II diabetes in the Breda cohort of 566 patients with an apparently low insulin use. It will be of great interest to see if this $t$-allele is associated with Type II diabetes mellitus and insulin use.

Acknowledgements. The authors would like to thank the participants of the Breda study for their cooperation. This study has been made possible by a grant from the Dutch Foundation for Diabetes Research (DFN97.114) to T. W. van Haeften and C. Wijmenga.

Yours faithfully,

J.H.O. van Tilburg, L. B. Rozeman, H. van Someren, C. A.E. Rigters-Aris, J. P. Freriks, P.L. Pearson, L. A. Sandkuijl, T.W. van Haeften, C. Wijmenga

\section{References}

1. 't Hart LM, de Knijff P, Dekker JM et al. (1999) Variants in the sulphonylurea receptor gene: association of the exon $16-3 t$ variant with Type II diabetes mellitus in Dutch Caucasians. Diabetologia 42: 617-620

2. Inoue H, Ferrer J, Welling CM et al. (1996) Sequence variants in the sulfonylurea receptor (SUR) gene are associated with NIDDM in Caucasians. Diabetes 45: 825-831

3. Hansen T, Echwald SM, Hansen L et al. (1998) Decreased tolbutamide-stimulated insulin secretion in healthy subjects with sequence variants in the high-affinity sulfonylurea receptor gene. Diabetes 47: 598-605

4. Lander ES, Schork NJ (1994) Genetic dissection of complex traits. Science 265: 2037-2048

5. Pritchard JK, Rosenberg NA (1999) Use of unlinked genetic markers to detect population stratification in association studies. Am J Hum Genet 65: 220-228

\section{Rising incidence of childhood diabetes is seen at all ages and in urban and rural settings in Yorkshire, United Kingdom}

Dear Sir,

The incidence of childhood Type I (insulin-dependent) diabetes mellitus in those under 5 years of age is rising in the United Kingdom and Europe but there has been conflicting evidence in the United Kingdom as to whether the rise is occurring in

Corresponding author: Dr. P. A. McKinney, Paediatric Epidemiology Group, 30 Hyde Terrace, Leeds LS2 9LN, UK all age groups. A study of 1037 children diagnosed between 1985 and 1996 from Oxford, United Kingdom [1] showed rising incidence was accounted for by children aged 0-4 years. A study of 2326 children diagnosed between 1984 and 1993 from Scotland, United Kingdom [2] has shown a rising incidence in all ages (0-14) and for each age-band (0-4, 5-9, 10-14). In Yorkshire, temporal trends between 1978 and 1993 showed the most statistically significant rise in 10-14 year olds [3].

In an extended data set we have investigated whether the incidence of childhood Type I diabetes in Yorkshire has continued to rise over the last 5 years, in which age groups and whether this is occurring differentially in urban and rural settings. Geographical variation in incidence is present in Yorkshire [4] and no previous studies have examined geographical differences in incidence over time. 